\title{
Humic Acid Promotes the Adsorption of Lead onto PSMPs: Site Energy Distribution Theory and Fluorescence Quenching Analysis
}

\section{Xiaotian Lu}

Sun Yat-sen University School of Chemistry

\section{Feng Zeng}

Sun Yat-Sen University School of Chemistry

\section{Shuyin Wei}

Sun Yat-Sen University School of Chemistry

Rui Gao

Sun Yat-sen University School of Chemistry

Abliz Abdurahman

Sun Yat-sen University School of Chemistry

Hao Wang

Sun Yat-sen University School of Chemistry

Weiqian Liang ( $\square$ liangwq3@mail2.sysu.edu.cn)

Sun Yat-Sen University School of Chemistry https://orcid.org/0000-0002-2329-3761

\section{Research Article}

Keywords: Polystyrene microplastics, Pb2+, Humic Acid, Site energy distribution, Fluorescence quenching

Posted Date: November 12th, 2021

DOI: https://doi.org/10.21203/rs.3.rs-995681/v1

License: (a) (i) This work is licensed under a Creative Commons Attribution 4.0 International License. Read Full License 


\section{Abstract}

Microplastics (MPs) have a great potential to adsorb heavy metal pollutants such as $\mathrm{Pb}^{2+}$ and the dissolved organic matter(DOM) in the aquatic environment will affect this adsorption behavior. In this study, batch experiments were performed to investigate the adsorption characteristics of $\mathrm{Pb}^{2+}$ onto polystyrene microplastics (PSMPs) in the presence and absence of HA(a kind of representative DOM). The adsorption kinetics of $\mathrm{Pb}^{2+}$ onto PSMPs conformed to the pseudo-second order model, and the adsorption isotherms were well fitted by the Langmuir model. With the increase of $\mathrm{HA}$ concentration, the $\mathrm{Pb}^{2+}$ adsorption onto PSMPs increased. Site energy distribution analysis showed that the presence of HA increased the adsorption site energy of PSMPs, thus enhancing the adsorption capacity for $\mathrm{Pb}^{2+}$. The fluorescence quenching analysis of HA further indicated that part of HA were adsorbed onto PSMPs, which increased additional binding sites on the surface of PSMPs. This was attributed to the abundant functional groups that could react with $\mathrm{Pb}^{2+}$ of $\mathrm{HA}$. The $\mathrm{pH}$ and ionic strength of solution changed the structure of $\mathrm{HA}$ and the adsorption sites of PSMPs, which influenced the adsorption capacity of PSMPs for $\mathrm{Pb}^{2+}$. This study illustrated the effect of $\mathrm{HA}$ on the process and mechanism of $\mathrm{Pb}^{2+}$ adsorption onto PSMPs, and provided more information for the evaluation of environmental behavior and toxicological effects of microplastics in aquatic environments.

\section{Introduction}

Microplastics (MPs) are defined as plastic fragments or particles with size less than $5 \mathrm{~mm}$ by the National Oceanic and Atmospheric Administration(Arthur et al. 2009). MPs consist of plastic microbeads that directly discharged into the environment (primary sources), and plastic fragments derived from the degrading of large plastics (secondary sources) due to weathering processes (e.g., UV photodegradation, mechanical abrasion, biodegradation, etc.) (Alimi et al. 2018). MPs always persist in the environment for a long time as the degradation processes are extremely slow, especially in water, where degradation can take place for decades(Desforges et al. 2014, Hidalgo-Ruz et al. 2012). In addition, MPs are easily driven by wind and water flow to acquire the ability of long-distance diffusion and migration to reach different regions, so they are widely distributed in aquatic environment such as the surface runoff, rivers and lakes as well as Marine(Tang et al. 2019, Tarnminga et al. 2016). MPs can accumulate in organisms through food chains, and cause a lot of adverse effects on aquatic and terrestrial organisms, including inhibited growth and development, endocrine disruption, immunity and neurotransmission dysfunction and so on(Lei et al. 2018, Lu et al. 2016, Rodriguez-Seijo et al. 2016). Furthermore, MPs can serve as vectors to accumulate and transport heavy metal pollutant due to their characteristics of small volume and large specific surface area, causing the bioaccumulation of contaminations and toxicants in aquatic environments(Brennecke et al. 2016, Hodson et al. 2017). The process and mechanism of the adsorption of heavy metals onto MPs has been studied in recent years(Gao et al. 2019, Wang et al. 2019, Wang et al. 2020a). For example, Gao et al. studied the adsorption process of $\mathrm{Pb}(\mathrm{II}), \mathrm{Cu}(\mathrm{II})$ and $\mathrm{Cd}(\mathrm{II})$ on $\mathrm{PP}, \mathrm{PE}, \mathrm{PA}, \mathrm{PVC}$, and POM microplastics through the laboratory test and the field test. Their experiment results showed that there were significant differences in the effects of different plastic types and locations on the adsorption rates and concentrations of heavy metals(Gao et al. 2019). 
Lead $(\mathrm{Pb}(\mathrm{II}))$ is one of the most representative heavy metal pollutants owing to its persistence in the environment, bioaccumulation and thus toxicity(Jozef et al. 2020). As a highly toxic metal, $\mathrm{Pb}(\mathrm{II})$ is seriously harmful to plant, animal and human healthy. Especially in contaminated water environments, $\mathrm{Pb}(\mathrm{II}) \mathrm{can}$ accumulate in various tissues of aquatic animals and plants that exposed to $\mathrm{Pb}$ (II) contamination, thereby influences morphological, physiological and biochemical processes(Bellinger and Needleman 2003 , Guo. 2002, Lee et al. 2019, Li et al. 2019a). Several studies have investigated the adsorption behavior of Pb(II) on MPs, as well as the effect factors of adsorption such as pH and ionic strength(Ahechti et al. 2020, Fu et al. 2020, Gao et al. 2019, Zou et al. 2020). Zou et al. (Zou et al. 2020) studied the sorption of three model heavy metals (i.e., $\mathrm{Cu}^{2+}, \mathrm{Cd}^{2+}$, and $\mathrm{Pb}^{2+}$ ) on $\mathrm{CPE}, \mathrm{PVC}, \mathrm{LPE}$ and $\mathrm{HPE}$, and found that $\mathrm{pH}$ can significantly affect the sorption of metals on MPs, but ionic strength exerted a relatively slight effect on this process. Ahechti et al. (Ahechti et al. 2020) evaluated the adsorption capacity of PE and PP for different metals (Cu, Cd, Pb and Zn) depending on the physicochemical conditions of the aquatic environments (exposure time, $\mathrm{pH}$, salinity). Their results showed that the adsorption percentages increased as $\mathrm{pH}$ increase and salinity decrease. Dissolved organic matter (DOM)in aquatic environment is also an important factor affecting the adsorption process. Godoy et al. investigated the adsorption of $\mathrm{Cd}, \mathrm{Co}, \mathrm{Cr}, \mathrm{Cu}, \mathrm{Ni}, \mathrm{Pb}$ and $\mathrm{Zn}$ by five different types of microplastics was performed in Milli-Q water and natural waters (seawater, urban wastewater and irrigation water), and found that an enhancement of metal adsorption in waters with high dissolved organic matter content as urban wastewater and irrigation water(Godoy et al. 2019). Humic Acid (HA) is a kind of representative dissolved organic matter (DOM) and widely exists in the water environment. HA contains a large number of oxygen-containing functional groups such as carboxyl and hydroxyl groups, which will interact with $\mathrm{Pb}(\mathrm{II})$ (Xiong et al. 2013). Our previous study has shown that HA can be adsorbed onto PSMPs in the aquatic environment through hydrophobic interaction and $\pi-\pi$ electron donor acceptor interaction(Abdurahman et al. 2020). When MPs, Pb(II) and HA coexist in solution, HA has different interactions with MPs and $\mathrm{Pb}(\mathrm{II})$, indicating its potential possibility to affect the adsorption of $\mathrm{Pb}(\mathrm{II})$ on microplastics. However, there is still a lack of associated mechanisms understanding on the effects of HA on the binding properties of $\mathrm{Pb}(\mathrm{II})$ to MPs.

In this study, polystyrene microplastics (PSMPs) were used as the model microplastics(Li et al. 2018) to study the interaction of $\mathrm{Pb}^{2+}$ with PSMPs and the effects of $\mathrm{HA}$ on the adsorption process. Adsorption kinetic and isotherm were conducted at different condition to researched the adsorption characteristic of $\mathrm{Pb}^{2+}$ adsorption. The site energy distribution theory and fluorescence quenching analysis of HA were used to explore the effect of HA on adsorption potentials of PSMPs to $\mathrm{Pb}^{2+}$. The results of this study helped to further understand the adsorption characteristics and mechanism of $\mathrm{Pb}^{2+}$ onto MPs, as well as providing more information for the evaluation of environmental behavior and toxicological effects of microplastics in aquatic environments.

\section{Materials And Methods}

\subsection{Materials and chemicals}


Polystyrene microplastics (PSMPs) and Aldrich Humic Acid (HA, sodium salt) were purchased from SigmaAldrich (St. Louis, MO, USA). The characteristics of PSMPs were reported in our previous study (Li et al. 2018). Lead nitrate $\left(\mathrm{Pb}\left(\mathrm{NO}_{3}\right)_{2}\right)$, sodium nitrate $\left(\mathrm{NaNO}_{3}\right)$, calcium nitrate $\left(\mathrm{Ca}\left(\mathrm{NO}_{3}\right)_{2}\right)$, nitric acid $\left(\mathrm{HNO}_{3}\right)$ and sodium hydroxide $(\mathrm{NaOH})$ were obtained from Guangzhou Chemical Reagent Co., LTD. (Guangzhou, China). All chemicals were of A.R. grade.

\subsection{Sample preparation}

The PSMPs were prepared into $50 \mathrm{mg} / \mathrm{L}$ suspension with ultrapure water $(18.2 \mathrm{M} \Omega)$. HA solution, obtained by dissolving $\mathrm{HA}$ sodium salt in $0.10 \mathrm{~mol} / \mathrm{L} \mathrm{NaOH}$ solution and stirred overnight at $27.0^{\circ} \mathrm{C}$, was adjusted to $\mathrm{pH} 7$ and then filtered through $0.45-\mu \mathrm{m}$ cellulose acetate filter paper (Millipore, Billerica, MA, USA). The filtrate was dialyzed with a dialysis membrane (500D) and finally stored at $\sim 4.0^{\circ} \mathrm{C}$ in the dark. The relevant characterization of $\mathrm{HA}$ is shown in the Supporting Information. $\mathrm{Pb}^{2+}$ stock solution $(500 \mathrm{mg} / \mathrm{L})$ was obtained by dissolving a known quantity of $\mathrm{Pb}\left(\mathrm{NO}_{3}\right)_{2}$ in distilled water. All the solution $\mathrm{pH}$ was adjusted using 0.10 $\mathrm{mol} / \mathrm{L} \mathrm{HNO}_{3}$ or $0.10 \mathrm{~mol} / \mathrm{L} \mathrm{NaOH}$ and measured by an Orion $\mathrm{pH} / \mathrm{ISE}$ meter (Model $710 \mathrm{~A}$, Thermo Fisher Scientific). The ionic strength was adjusted by adding $\mathrm{NaNO}_{3}$ or $\mathrm{Ca}\left(\mathrm{NO}_{3}\right)_{2}$ solution, respectively.

\subsection{Adsorption experiments}

Batch adsorption experiments were employed as described previously with minor modifications(Abdurahman et al. 2020). The adsorption kinetic experiments of $\mathrm{Pb}^{2+}$ uptake on PSMPs were carried out by adding PSMPs suspension, $\mathrm{Pb}^{2+}$ stock solution and HA solution into $300 \mathrm{~mL}$ conical flask. The initial $\mathrm{Pb}^{2+}$ concentration was $5.00 \mathrm{mg} / \mathrm{L}$ and the $\mathrm{HA}$ concentrations were $0.00,1.00,2.50,5.00 \mathrm{mg} \cdot \mathrm{C} / \mathrm{L}$, respectively. The suspensions were equilibrated on a reciprocating shaker (Shanghai Tensuc Ltd., China) at $27.0^{\circ} \mathrm{C}$ (room temperature) in the dark and sampled at different time within 0-4.0 $\mathrm{h}$. For the adsorption isotherm experiment, the initial $\mathrm{Pb}^{2+}$ concentration was $0.50-15.0 \mathrm{mg} / \mathrm{L}$, and the equilibrium time set at $4.0 \mathrm{~h}$ based on preliminary kinetic experiments resulted. The experiment $\mathrm{pH}$ value was selected for 3.0 and 6.0 , and the ionic strength was set with $0.01,1.00$ and $10.0 \mathrm{mmol} / \mathrm{L}$ for $\mathrm{NaNO}_{3}$, and $0.03,0.33$ and $3.33 \mathrm{mmol} / \mathrm{L}$ for $\mathrm{Ca}\left(\mathrm{NO}_{3}\right)_{2}$. At the end of the equilibration time, the suspensions were collected and filtered with a $0.45-\mu \mathrm{m}$ filter membrane, which part of the filtrate is used for $\mathrm{Pb}^{2+}$ concentration determination with AAS (Z-2000, Hitachi, Japan), and the other part is used for HA fluorescence detection (RF-5301PC, Shimadzu, Japan). The adsorption amounts of $\mathrm{Pb}^{2+}$ adsorbed on PSMPs were calculated from the differences between the initial and final $\mathrm{Pb}^{2+}$ concentrations in solutions; mass losses for control samples were negligible $(<1 \%)$.

The adsorption process of $\mathrm{Pb}^{2+}$ on $\mathrm{HA}$ was described in Supplementary data.

The experiments for each condition were performed in triplicate and took the average.

\subsection{Analytical method}

The zeta potential of PSMPs at different background ionic conditions $\left(\mathrm{Na}^{+}\right.$or $\left.\mathrm{Ca}^{2+}\right)$ were analyzed by Zeta potential analyzer (BI-PALS, Brookhaven, American) at the range of $\mathrm{pH}$ 2.0-10.0. The elemental analysis (C口 $\mathrm{H} \square \mathrm{N} \square \mathrm{O} \square S$ ) of HA was characterized using Elemental analyzer (Vario EL cube, Elementar, Germany). The functional groups (carboxyl and hydroxyl) of HA were determined using Ma's work(Ma et al. 2001). The 
concentration of HA was measured by TOC analyzer (TOC-L CPH, Shimadzu, Japan). Fluorescence excitation (Ex)-emission (Em) matrix (EEM) spectra of HA was measured using a fluorescence spectrometer (RF-5301PC, Shimadzu, Japan).

Details of the data analysis for $\mathrm{Pb}^{2+}$ adsorption onto PSMPs are given in the Supplementary data.

\section{Results And Discussion}

\subsection{Adsorption kinetics of $\mathrm{Pb}^{2+}$ onto PSMPs in the presence and absence of HA}

The adsorption kinetic curves of $\mathrm{Pb}^{2+}$ onto PSMPs at different initial HA concentrations with varying solution conditions (i.e., $\mathrm{pH}$ and ionic strength) were illustrated in Fig. S1 and S2. The adsorption of $\mathrm{Pb}^{2+}$ onto PSMPs under different conditions showed similar kinetic behaviors, i.e., the uptake of $\mathrm{Pb}^{2+}$ is rapid in the time range of $0 \sim 60 \mathrm{~min}$, then the adsorption decreases gradually and finally reach equilibrium. At the initial adsorption stage, $\mathrm{Pb}^{2+}$ occupied the abundant adsorbing sites of PSMPs. With prolonged contact time, most of the adsorption sites were occupied, and the adsorption rate of $\mathrm{Pb}^{2+}$ became slower as well as the adsorption reaches equilibrium gradually(Wang et al. 2019). Therefore, the adsorption equilibrium time was set to 240 min, which was sufficient for $\mathrm{Pb}^{2+}$ adsorption.

The pseudo-first-order and pseudo-second-order kinetic models were used to fit the experimental data. Kinetic parameters were listed in Table S1 and S2. The $\mathrm{R}^{2}$ values for the pseudo-second-order kinetic model were higher than that for the pseudo-first-order model, indicating that the pseudo-second-order kinetic model was better fitted the experimental data than the pseudo-first-order kinetic model in different experiment conditions, and the chemical sorption may be rate-limiting step of $\mathrm{Pb}^{2+}$ adsorption mechanism(Tang et al. 2019). The $Q_{e}$ and initial adsorption rate $V_{0}$ increased with the increase of $\mathrm{pH}$ and decrease of ionic strength, showing that the higher $\mathrm{pH}$ value and lower ionic strength would promote the adsorption of $\mathrm{Pb}^{2+}$ onto PSMPs. Similar trends were previously reported for the adsorption of $\mathrm{Pb}^{2+}$ or other heavy metal on kinds of adsorbent materials (Fu et al. 2020, Zheng et al. 2018, Zou et al. 2020). At the identical pH and ionic strength condition, the presence of $\mathrm{HA}$ significantly increased the adsorption amount of $\mathrm{Pb}^{2+}$ on PSMPs. For example, at the condition of $\mathrm{pH} 6.0$ and $0.10 \mathrm{mmol} / \mathrm{L} \mathrm{NaNO}_{3}$, the $\mathrm{Q}_{\mathrm{e}}$ of $\mathrm{Pb}^{2+}$ increased from 0.302 to $0.888,1.41$ and $1.76 \mathrm{mg} / \mathrm{g}$ at the concentration of $1.00,2.50$ and $5.00 \mathrm{mg} \cdot \mathrm{C} / \mathrm{L}$ of HA, respectively. HA adsorbed on PSMPs would introduce more oxygen-containing functional groups such as hydroxyl and carboxyl groups, which were available for the formation of strong complexes with $\mathrm{Pb}^{2+}$, so that more $\mathrm{Pb}^{2+}$ was adsorbed onto PSMPs(Yang et al. 2011).

\subsection{Adsorption isotherms of $\mathrm{Pb}^{2+}$ onto PSMPs in the presence and absence of HA}

The isothermal adsorption curves reveal the equilibrium state of adsorbate in solution and adsorbent, and further illustrate the adsorption mechanism(Shen et al. 2021). Fig. S3 and S4 showed the adsorption 
isotherm process of $\mathrm{Pb}^{2+}$ onto PSMPs in the absence and presence of $\mathrm{HA}$. It could be seen that the equilibrium adsorption capacity of PSMPs for $\mathrm{Pb}^{2+}$ rapidly rose at first due to the relatively strong driving force at high initial concentrations(Qiao et al. 2016). Then the upward trend slew down with the initial $\mathrm{Pb}^{2+}$ concentration increased. This was because a large number of adsorption sites are already occupied by $\mathrm{Pb}^{2+}$. In order to forecast adsorption behavior, the Langmuir and Freundlich isotherm models were used to fit the adsorption curve, respectively, and the fitting parameters were listed at Table S3 and S4. Both two isotherm models could fit the adsorption process well, and the $\mathrm{R}^{2}$ values for the Langmuir model were higher than Freundlich model. Therefore, the Langmuir model could be better employed for characterizing equilibrium adsorption of $\mathrm{Pb}^{2+}$ on PSMPs with/without addition of $\mathrm{HA}$. In addition, the fitting results implied that the chemisorption and monolayer adsorption played a significant role in the $\mathrm{Pb}^{2+}$ removal(Jinren et al. 2014, Wang et al. 2020).

$\mathrm{K}_{\mathrm{L}}$ is related to the adsorption affinity between adsorbate and adsorbent. In Table S3 and S4, the significantly increased of $K_{L}$ indicated that the presence of $H A$ enhanced the adsorption affinity and capacity of PSMPS for $\mathrm{Pb}^{2+}$ ( $\mathrm{Li}$ et al. 2019). The change of $\mathrm{K}_{\mathrm{L}}$ also indicated that the adsorption of $\mathrm{Pb}^{2+}$ onto PSMPs was influenced by the solution conditions such as pH and ionic strength(Tang et al. 2019). As for Freundlich model, the $\mathrm{n}$ values of all experiment conditions were higher than 1 , suggesting that the adsorption of $\mathrm{Pb}^{2+}$ onto PSMPs was greatly nonlinear. The distribution of adsorption sites on the PSMPs is heterogeneous, and electrostatic interactions was major adsorption mechanisms(Xu et al. 2018, Sun et al. 2010, Wang et al. 2020). These results indicated that the adsorption mechanism of heavy metals onto PSMPs was mainly includes both physical adsorption and chemical bonding between anion and cation(Luo et al. 2022).

\subsection{Effect of different $\mathrm{HA}$ concentration on $\mathrm{Pb}^{2+}$ adsorption onto PSMPs}

Figure $\mathrm{S} 3$ and $\mathrm{S} 4$ showed the isothermal adsorption process of $\mathrm{Pb}^{2+}$ onto PSMPs with different HA concentration, and comparison of Langmuir model parameters $\left(K_{L}\right.$ and $\left.Q_{m}\right)$ were shown in Fig. 1. The changing of $K_{L}$ and $Q_{m}$ illustrated that the adsorption capacities of PSMPs was significantly influenced by the presence of $H A$. With the increase of $H A$ concentration, $K_{L}$ and $Q_{m}$ increased accordingly, indicating that the existence of HA promoted the adsorption capacity of PSMPs for $\mathrm{Pb}^{2+}$. For example, the adsorption amount of $\mathrm{Pb}^{2+}$ on PSMPs increased from 0.443 to $2.13 \mathrm{mg} / \mathrm{g}$ when the HA concentrations were 0.00 to 5.00 $\mathrm{mg} \cdot \mathrm{C} / \mathrm{L}$, with the condition of $\mathrm{pH} 6.0$ and $0.10 \mathrm{mmol} / \mathrm{L} \mathrm{NaNO}$. The results were consistent with other heavy metal adsorption in previous studies(Li et al. 2019, Yang et al. 2014). Li et al. (Li et al. 2019) found that the HA affected the adsorption of Cd on PS and PVC microplastics. Yang et al. (Yang et al. 2014) demonstrated that the presence of HA was beneficial to the adsorption of FRGO and FGO for copper ions because of the adsorption of $\mathrm{HA}$ on FRGO and FGO introduced new adsorption sites for $\mathrm{Cu}(\mathrm{II})$ binding.

The interaction between PSMPs and HA was researched in our reported works(Abdurahman et al. 2020). The results showed that the adsorption of HA on PSMPs conformed to pseudo-second-order kinetic model and Freundlich model, indicating that HA adsorbed on PSMPs surface through hydrophobic and $\pi-\pi$ interaction. The adsorption process was low pH-dependent, and the adsorption capacity of PSMPs increased with the 
increase of ionic strength. Previous studies showed that HAs is an important natural ligands in regulating the speciation, bioavailability, and ultimate fate of trace metal element in the environment(Kováik et al. 2018, Prado et al. 2006). This was because of the numerous functional groups (- $\mathrm{COOH}$ and $-\mathrm{OH})$ in $\mathrm{HA}$ molecules, which could combine with heavy metal ions such as $\mathrm{Pb}^{2+}$ to form stable compounds by means of complexation, ion exchange and electrostatic interaction(Bradl 2004, Yang et al. 2015). The elemental analysis and determination of carboxyl and hydroxyl groups of HA were determined and the results were summarized at Table S5, which was similar to others works(Tan et al. 2013). Then the adsorption experiments of $\mathrm{Pb}^{2+}$ on $\mathrm{HA}$ were conducted and the adsorption kinetic and isotherm curves were shown in Fig. S5 and S6, as well as the fitting parameters were shown in Table S6 and S7. The adsorption of $\mathrm{Pb}^{2+}$ on HA was fitted to pseudo-second-order kinetic model and Langmuir model.

According to the different kinetic adsorption processes of $\mathrm{Pb}^{2+}$ on PSMPs and HA (Fig. S1, S2 and S5), the adsorption equilibrium of $\mathrm{Pb}^{2+}$ on $\mathrm{HA}$ was faster than that onto PSMPs. When PSMPs, $\mathrm{HA}$ and $\mathrm{Pb}^{2+}$ coexisted in the solution, $\mathrm{Pb}^{2+}$ was more prone to combine with $\mathrm{HA}$ to achieve adsorption equilibrium than PSMPs. Then HA-Pb ${ }^{2+}$ complex adsorbed onto PSMPs through the interaction between HA and PSMPs, which led to an indirect adsorption of $\mathrm{Pb}^{2+}$ onto PSMPs. Besides, the free $\mathrm{Pb}^{2+}$ without binding to $\mathrm{HA}$ also adsorbed directly onto PSMPs due to electrostatic interaction, until the concentration of $\mathrm{Pb}^{2+}$ in the two phases reached equilibrium.

Another possibility was that part of HA molecules first adsorbed on the surface of PSMPs, which introduced more functional groups $(-\mathrm{COOH}$ and $-\mathrm{OH})$, and functioned as anchors and aid adsorption in the adsorption of $\mathrm{Pb}^{2+}$ (Qi et al. 2021). The negative charged functional groups (- $\mathrm{COOH}$ and $-\mathrm{OH}$ ) of $\mathrm{HA}$ increased the negative charge of PSMPs surface when combined with PSMPs(Li et al. 2019, Lu et al. 2018), and thus enhancing the electrostatic interaction between PSMPs and $\mathrm{Pb}^{2+}$ (Tan et al. 2021). This principle was similar to the biofilm on the surface of microplastics(Wang et al. 2020).

\subsubsection{Effect of $\mathrm{pH}$ on $\mathrm{Pb}^{2+}$ adsorption onto PSMPs in the presence and absence of HA}

The solution $\mathrm{pH}$ can affect the surface charge of adsorbents, the structure of $\mathrm{HA}$ and the ionic species of metals, thereby influence the underlying mechanisms involved in the interaction among different substances in the adsorption process(Yang et al. 2014). Therefore, the adsorption of $\mathrm{Pb}^{2+}$ on PSMPs with or without HA at different $\mathrm{pH}$ value were studied. As shown in Fig. 1, the $\mathrm{Q}_{\mathrm{m}}$ of $\mathrm{Pb}^{2+}$ adsorption on PSMPs increased with the increasing solution $\mathrm{pH}$ value whether $\mathrm{HA}$ existed or not. At the condition of $0.10 \mathrm{mmol} / \mathrm{L} \mathrm{NaNO}_{3}$ and 5.00 $\mathrm{mg} \cdot \mathrm{C} / \mathrm{L} \mathrm{HA}$, the equilibrium adsorption amount of $\mathrm{Pb}^{2+}$ increased from 1.94 to $2.13 \mathrm{mg} / \mathrm{g}$ when pH value was from 3.0 to 6.0 , indicating that a higher $\mathrm{pH}$ was beneficial to the adsorption of $\mathrm{Pb}^{2+}$ on PSMPs.

The effect of $\mathrm{pH}$ on adsorption is related to the surface charge of PSMPs. Fig. S7 showed that the zeta potential of PSMPs gradually decreased with the increase of $\mathrm{pH}$ in the range of $\mathrm{pH} 2.0-10.0$. The $\mathrm{pH}_{\mathrm{pzc}}$ of PSMPs were $1.06,1.51$ and 2.18 at the conditions of $0.10,1.00$ and $10.0 \mathrm{mmol} / \mathrm{L} \mathrm{NaNO}{ }_{3}$, as well as 1.47 , 
1.72 and 2.19 at the conditions of $0.03,0.33$ and $3.33 \mathrm{mmol} / \mathrm{L} \mathrm{Ca}\left(\mathrm{NO}_{3}\right)_{2}$, respectively (Table S8). That was to say, the $\mathrm{pH}_{\mathrm{pzc}}$ of PSMPs increased with the increase of ionic strength.

In the binary system without HA, PSMPs was negatively charged and it was easy to attract positively charged $\mathrm{Pb}^{2+}$ through electrostatic interaction at the experimental $\mathrm{pH}$ conditions $(\mathrm{pH} 3.0$ and $\mathrm{pH} 6.0)$ (Wang et al. 2020). The negative charges of PSMPs increased as $\mathrm{pH}$ increased, which led to the enhancement of electrostatic interaction between PSMPs and $\mathrm{Pb}^{2+}$ correspondingly, and enhanced the adsorption capacity of PSMPs(Tang et al. 2019). The decrease in $\mathrm{pH}$ also causes competitive adsorption. There was a large amount of hydronium ion $\mathrm{H}_{3} \mathrm{O}^{+}$in the solution under low $\mathrm{pH}$ conditions, which competed with $\mathrm{Pb}^{2+}$ for the adsorption sites on the surface of PSMPs, and inhibited the adsorption of $\mathrm{Pb}^{2+}$ (Bardestani et al. 2019, Wang 2011). Similar trends were reported for the adsorption of metal ions on other microplastics, as well as some kind of nanomaterials(Jinren et al. 2014, Wang et al. 2019, Zhao et al. 2011).

When $\mathrm{HA}$ was present in solution, the $\mathrm{pH}$ value influenced the adsorption capacity of $\mathrm{Pb}^{2+}$ on $\mathrm{PSMPs}$ and the binding characteristics of $\mathrm{HA}$ and $\mathrm{Pb}^{2+}$. The adsorption of $\mathrm{HA}$ onto PSMPs was little affected by $\mathrm{pH}$, but the adsorption of $\mathrm{Pb}^{2+}$ on $\mathrm{HA}$ increased with the increase of $\mathrm{pH}$ value. The molecular structure of $\mathrm{HA}$ was affected by the $\mathrm{pH}$ value of solution, i.e., with the decreasing of $\mathrm{pH}$, the stretched linear HA structure gradually curled and became a compacted form. Therefore, the exposed functional groups of HA were reduced and the binding with $\mathrm{Pb}^{2+}$ was weakened under low $\mathrm{pH}$ condition(Gezici et al. 2007). In ternary systems, the presence of $\mathrm{HA}$ further increased the effect of high $\mathrm{pH}$ to promote the adsorption of $\mathrm{Pb}^{2+}$ onto PSMPs. In general, whether $\mathrm{HA}$ is present or not, the increase of $\mathrm{pH}$ is favorable to the adsorption of $\mathrm{Pb}^{2+}$ on PSMPs.

\subsubsection{Effect of ionic strength on $\mathrm{Pb}^{2+}$ adsorption onto PSMPs in the presence and absence of HA}

The ionic strength of aquatic environmental can affect the adsorption behaviors of $\mathrm{Pb}^{2+}$ onto PSMPs, whether HA exist or not. Fig. 1 showed that the adsorption capacities of $\mathrm{Pb}^{2+}$ onto PSMPs decreased with the increase of ionic strength at different $\mathrm{HA}$ concentration. For instence, the $\mathrm{Q}_{\mathrm{m}}$ of $\mathrm{Pb}^{2+}$ decreased from 2.13 to 1.57 , and from 1.97 to $1.42 \mathrm{mg} / \mathrm{g}$ as the concentration of $\mathrm{Na}^{+}$and $\mathrm{Ca}^{2+}$ increased under the condition of $\mathrm{pH} 6.0$ and $5.00 \mathrm{mg} \cdot \mathrm{C} / \mathrm{L} \mathrm{HA}$, showing that the presence of background ions is not conducive to the adsorption of $\mathrm{Pb}^{2+}$. The results were similar to the previous studies(Fu et al. 2020, Holmes et al. 2014, Zou et al. 2020).

Figure $\mathrm{S} 7$ showed that the $\mathrm{pH}_{\mathrm{pzc}}$ of PSMPs increased with the increase of ionic strength, because the positively charged background ions $\left(\mathrm{Na}^{+}\right.$or $\mathrm{Ca}^{2+}$ ) would shiel or neutralize the negative surface charges of PSMPs(Wijesena et al. 2020). What's more, the effect of $\mathrm{Ca}^{2+}$ on the $\mathrm{pH}_{\mathrm{pzc}}$ of PSMPs is greater than that of $\mathrm{Na}^{+}$under the same ionic strength condition. This is because the charge shielding or neutralization effect of divalent positive ions is stronger than that of mono-valent positive ions. When the ionic strength increased, the surface negative charge of PSMPs would reduce, which resulted in the weakening of electrostatic interaction between PSMPs and $\mathrm{Pb}^{2+}$. In addition, according to the theory of DLVO, increasing the ionic strength of the solution will compress the electric double layer and reduce the electrostatic repulsion, 
resulting in an increase in the aggregation of PSMPs and a decrease in the effective adsorption sites(Alimi et al. 2018, Li et al. 2018). A similar phenomenon has been found in the adsorption of metals by carbon-based nanomaterials such as graphene oxide and carbon oxide nanotubes(Yang et al. 2011). Besides, background electrolyte ions $\left(\mathrm{Na}^{+}\right.$and $\mathrm{Ca}^{2+}$ ) can also compete with $\mathrm{Pb}^{2+}$ for specific available adsorption sites on PSMPs, which may be one of the reasons for the weakened adsorption of $\mathrm{Pb}^{2+}$ (Wang et al. 2016, Zhao et al. 2011).

\subsection{Effects mechanisms of $\mathrm{HA}$ on $\mathrm{Pb}^{2+}$ adsorption onto PSMPs}

\subsubsection{Site energy distribution analysis}

The SEDT (site energy distribution theory) provides relevant information on the energy distribution of the adsorbent surface site, the average site energy and the energy distribution heterogeneity, which can further explain the mechanism of adsorption behavior(Carter et al. 1995). According to the SEDT, the energy distribution of adsorption sites on the surface of adsorbents is heterogeneous, and sites with higher adsorption energy are more likely to be occupied by adsorbents. Fig S8 and S9 showed the effect of HA on the site energy $\mathrm{E}^{\star}$, and Fig. 2 and 3 showed the site energy distribution function $\mathrm{F}\left(\mathrm{E}^{\star}\right)$ of $\mathrm{Pb}^{2+}$ adsorption on PSMPs under different condition based on Langmuir model.

It can be seen from the Fig S8 and $S 9$ that the $E^{\star}$ values gradually decreased with the increase of equilibrium adsorption amount of $\mathrm{Pb}^{2+}$ on PSMPs, indicating that the surface energy distribution of PSMPs is heterogeneous, and the amount of high energy sites is limited. In the adsorption process of ternary systems, the high-energy adsorption sites on PSMPs were firstly occupied by $\mathrm{Pb}^{2+}$ or $\mathrm{HA}-\mathrm{Pb}^{2+}$, then the low-energy adsorption sites(Shi et al. 2013). This is consistent with the adsorption of $\operatorname{Cr}(\mathrm{VI})$ on engineered silicate nanoparticles(Liao et al. 2020). In addition, with the increase of HA concentration, the $E^{\star}$ values increased, illustrated that the presence of HA enhanced the adsorption site energy on the PSMPs surface, thus promoting the adsorption of $\mathrm{Pb}^{2+}$.

From Fig. 2 and 3 , the $\mathrm{F}\left(\mathrm{E}^{\star}\right)$ curves of $\mathrm{Pb}^{2+}$ adsorption on PSMPs were all unimodal and quasiGaussian(Huang et al. 2018). Relevant parameters such as $E m^{\star}, F\left(E m^{\star}\right), \mu\left(E^{\star}\right)$ and $\sigma_{e}{ }^{*}$ were shown in the Table 1 and 2. It was reported that the higher the value of the $\mu\left(E^{\star}\right)$, the higher the adsorption affinity (Carter et al. 1995). With the increasing $\mathrm{pH}$ value and decreasing ionic strength, the parameters of $E m^{\star}, F\left(E m^{\star}\right)$ and $\mu\left(E^{\star}\right)$ were slightly increased, which was consistent with the adsorption kinetics and isothermal results. The results again reflected the effect of $\mathrm{pH}$ and ionic strength on the adsorption of $\mathrm{Pb}^{2+}$ to PSMPs. When the HA concentration increased, the parameters increased significantly, indicating that the presence of HA enhanced the adsorption affinity of PSMPs for $\mathrm{Pb}^{2+}$. Evidenced by the site energy distribution (Fig. 2 and 3 ), the site energy heterogeneity was revealed for adsorption of $\mathrm{Pb}^{2+}$ on PSMPs and could be characterized by the standard deviation $\sigma_{\mathrm{e}}{ }^{*}$ of the distribution(Yan et al. 2017). The $\sigma_{\mathrm{e}}{ }^{*}$ value was 10.2 under different conditions, indicating that the surface of PSMPs was with high adsorption heterogeneous, and the surface heterogeneity of PSMPs were close, that is, the addition of HA did not change the surface structure of PSMPs. 
Table 1

Site energy distribution parameters of $\mathrm{Pb}^{2+}$ adsorption onto PSMPs (pH 3.0)

\begin{tabular}{|c|c|c|c|c|c|}
\hline $\begin{array}{l}\mathrm{C}_{\mathrm{HA}} \\
(\mathrm{mg} \cdot \mathrm{C} / \mathrm{L})\end{array}$ & $\begin{array}{l}\text { Ionic Strength } \\
\text { (mmol/L) }\end{array}$ & $\mathrm{E}_{\mathrm{m}}^{*}(\mathrm{KJ} / \mathrm{mol})$ & $\mathrm{F}\left(\mathrm{E}_{\mathrm{m}}{ }^{*}\right)(\mathrm{mg} \cdot \mathrm{mol} /(\mathrm{g} \cdot \mathrm{KJ}))$ & $\mu\left(E^{*}\right)(K J / m o l)$ & $\sigma^{*}(\mathrm{KJ} / \mathrm{mol})$ \\
\hline \multirow[t]{6}{*}{0.00} & $0.100^{\mathrm{a}}$ & 29.8 & 0.0398 & 29.8 & 10.2 \\
\hline & $1.00^{\mathrm{a}}$ & 29.6 & 0.0379 & 29.6 & 10.2 \\
\hline & $10.0^{\mathrm{a}}$ & 29.1 & 0.0348 & 29.2 & 10.2 \\
\hline & $0.0300^{\mathrm{b}}$ & 29.6 & 0.0356 & 29.6 & 10.2 \\
\hline & $0.330^{b}$ & 29.5 & 0.0298 & 29.5 & 10.2 \\
\hline & $3.33^{b}$ & 29.1 & 0.0280 & 29.1 & 10.2 \\
\hline \multirow[t]{6}{*}{1.00} & $0.100^{\mathrm{a}}$ & 31.6 & 0.111 & 31.6 & 10.2 \\
\hline & $1.00^{\mathrm{a}}$ & 31.1 & 0.0980 & 31.1 & 10.2 \\
\hline & $10.0^{\mathrm{a}}$ & 30.8 & 0.0840 & 30.8 & 10.2 \\
\hline & $0.0300^{\mathrm{b}}$ & 31.2 & 0.105 & 31.2 & 10.2 \\
\hline & $0.330^{b}$ & 30.9 & 0.0918 & 30.9 & 10.2 \\
\hline & $3.33^{b}$ & 30.7 & 0.0788 & 30.7 & 10.2 \\
\hline \multirow[t]{6}{*}{2.50} & $0.100^{\mathrm{a}}$ & 31.7 & 0.163 & 31.7 & 10.2 \\
\hline & $1.00^{\mathrm{a}}$ & 31.3 & 0.140 & 31.3 & 10.2 \\
\hline & $10.0^{\mathrm{a}}$ & 30.8 & 0.123 & 30.8 & 10.2 \\
\hline & $0.0300^{b}$ & 31.3 & 0.154 & 31.3 & 10.2 \\
\hline & $0.330^{\mathrm{b}}$ & 31.0 & 0.136 & 31.0 & 10.2 \\
\hline & $3.33^{b}$ & 30.4 & 0.114 & 30.4 & 10.2 \\
\hline \multirow[t]{4}{*}{5.00} & $0.100^{\mathrm{a}}$ & 32.8 & 0.195 & 32.8 & 10.2 \\
\hline & $1.00^{\mathrm{a}}$ & 32.4 & 0.175 & 32.4 & 10.2 \\
\hline & $10.0^{\mathrm{a}}$ & 32.0 & 0.147 & 32.0 & 10.2 \\
\hline & $0.0300^{\mathrm{b}}$ & 32.5 & 0.183 & 32.5 & 10.2 \\
\hline
\end{tabular}

${ }^{\mathrm{a}} \mathrm{NaNO}_{3},{ }^{\mathrm{b}} \mathrm{Ca}\left(\mathrm{NO}_{3}\right)_{2}$ 


\begin{tabular}{|cccccc|}
\hline $\begin{array}{l}\mathrm{C}_{\mathrm{HA}} \\
(\mathbf{m g} \cdot \mathrm{C} / \mathrm{L})\end{array}$ & $\begin{array}{l}\text { lonic Strength } \\
(\mathrm{mmol} / \mathrm{L})\end{array}$ & $\mathrm{E}_{\mathrm{m}}{ }^{*}(\mathrm{KJ} / \mathrm{mol})$ & $\mathrm{F}\left(\mathrm{E}_{\mathrm{m}}{ }^{*}\right)(\mathrm{mg} \cdot \mathrm{mol} /(\mathrm{g} \cdot \mathrm{KJ}))$ & $\mu\left(\mathrm{E}^{*}\right)(\mathrm{KJ} / \mathrm{mol})$ & $\boldsymbol{\sigma}^{*}(\mathrm{KJ} / \mathrm{mol})$ \\
\hline $0.330^{\mathrm{b}}$ & 32.3 & 0.162 & 32.3 & 10.2 \\
\hline $3.33^{\mathrm{b}}$ & 31.8 & 0.137 & 31.8 & 10.2 \\
\hline${ }^{\mathrm{a} N a N_{3},}{ }^{\mathrm{b}} \mathrm{Ca}\left(\mathrm{NO}_{3}\right)_{2}$ & & & & \\
\hline
\end{tabular}


Table 2

Site energy distribution parameters of $\mathrm{Pb}^{2+}$ adsorption onto PSMPs ( $\mathrm{pH}$ 6.0)

\begin{tabular}{|c|c|c|c|c|c|}
\hline $\begin{array}{l}\mathrm{C}_{\mathrm{HA}} \\
(\mathrm{mg} \cdot \mathrm{C} / \mathrm{L})\end{array}$ & $\begin{array}{l}\text { lonic Strength } \\
\text { (mmol/L) }\end{array}$ & $\mathrm{E}_{\mathrm{m}}^{*}(\mathrm{KJ} / \mathrm{mol})$ & $\mathrm{F}\left(\mathrm{E}_{\mathrm{m}}{ }^{*}\right)(\mathrm{mg} \cdot \mathrm{mol} /(\mathrm{g} \cdot \mathrm{KJ}))$ & $\mu\left(E^{\star}\right)(K J / m o l)$ & $\sigma^{*}(\mathrm{KJ} / \mathrm{mol})$ \\
\hline \multirow[t]{6}{*}{0.00} & $0.100^{\mathrm{a}}$ & 30.7 & 0.0444 & 30.7 & 10.2 \\
\hline & $1.00^{\mathrm{a}}$ & 30.3 & 0.0420 & 30.3 & 10.2 \\
\hline & $10.0^{\mathrm{a}}$ & 29.9 & 0.0382 & 29.9 & 10.2 \\
\hline & $0.0300^{\mathrm{b}}$ & 30.2 & 0.0407 & 30.2 & 10.2 \\
\hline & $0.330^{b}$ & 29.8 & 0.0365 & 29.8 & 10.2 \\
\hline & $3.33^{\mathrm{b}}$ & 29.2 & 0.0361 & 29.2 & 10.2 \\
\hline \multirow[t]{6}{*}{1.00} & $0.100^{a}$ & 32.2 & 0.123 & 32.2 & 10.2 \\
\hline & $1.00^{\mathrm{a}}$ & 32.1 & 0.106 & 32.1 & 10.2 \\
\hline & $10.0^{\mathrm{a}}$ & 31.1 & 0.0967 & 31.1 & 10.2 \\
\hline & $0.0300^{b}$ & 32.1 & 0.113 & 32.1 & 10.2 \\
\hline & $0.330^{b}$ & 31.7 & 0.0999 & 31.7 & 10.2 \\
\hline & $3.33^{\mathrm{b}}$ & 31.1 & 0.0897 & 31.1 & 10.2 \\
\hline \multirow[t]{6}{*}{2.50} & $0.100^{\mathrm{a}}$ & 32.5 & 0.185 & 32.5 & 10.2 \\
\hline & $1.00^{\mathrm{a}}$ & 32.2 & 0.163 & 32.2 & 10.2 \\
\hline & $10.0^{\mathrm{a}}$ & 31.2 & 0.148 & 31.2 & 10.2 \\
\hline & $0.0300^{b}$ & 32.2 & 0.175 & 32.2 & 10.2 \\
\hline & $0.330^{b}$ & 32.1 & 0.151 & 32.1 & 10.2 \\
\hline & $3.33^{\mathrm{b}}$ & 31.2 & 0.135 & 31.2 & 10.2 \\
\hline \multirow[t]{4}{*}{5.00} & $0.100^{\mathrm{a}}$ & 33.1 & 0.213 & 33.1 & 10.2 \\
\hline & $1.00^{\mathrm{a}}$ & 33.0 & 0.182 & 33.0 & 10.2 \\
\hline & $10.0^{\mathrm{a}}$ & 32.9 & 0.157 & 32.9 & 10.2 \\
\hline & $0.0300^{b}$ & 33.0 & 0.197 & 33.0 & 10.2 \\
\hline
\end{tabular}

${ }^{\mathrm{a}} \mathrm{NaNO}_{3},{ }^{\mathrm{b}} \mathrm{Ca}\left(\mathrm{NO}_{3}\right)_{2}$ 


\begin{tabular}{|c|c|c|c|c|c|}
\hline $\begin{array}{l}\mathrm{C}_{\mathrm{HA}} \\
(\mathrm{mg} \cdot \mathrm{C} / \mathrm{L})\end{array}$ & $\begin{array}{l}\text { Ionic Strength } \\
(\mathrm{mmol} / \mathrm{L})\end{array}$ & $\mathrm{E}_{\mathrm{m}}{ }^{*}(\mathrm{KJ} / \mathrm{mol})$ & $\mathrm{F}\left(\mathrm{E}_{\mathrm{m}}{ }^{*}\right)(\mathrm{mg} \cdot \mathrm{mol} /(\mathrm{g} \cdot \mathrm{KJ}))$ & $\mu\left(E^{*}\right)(\mathrm{KJ} / \mathrm{mol})$ & $\sigma^{*}(\mathrm{KJ} / \mathrm{mol})$ \\
\hline & $0.330^{\mathrm{b}}$ & 33.0 & 0.166 & 33.0 & 10.2 \\
\hline & $3.33^{b}$ & 32.8 & 0.142 & 32.8 & 10.2 \\
\hline
\end{tabular}

\subsubsection{Fluorescence quenching analysis of HA}

Figure S10 showed the 3DEEM (three-dimensional fluorescence excitation-emission matrix) spectra of $\mathrm{HA}$, indicating that the texted HA molecules had two main fluorescence peaks, i.e., peak A (Ex/Em: 275/481 nm) and peak $B(E x / E m: ~ 455 / 516 \mathrm{~nm})$. Peak $A$ with high intensity was the fluorescence peak of terrestrial humiclike, while peak B had a lower intensity, which might be related to microbial metabolism(Coble. 1996). Peak A with higher intensity was selected for fluorescence quenching analysis.

In binary $\mathrm{HA}-\mathrm{Pb}^{2+}$ system and ternary PSMPs-HA- $-\mathrm{Pb}^{2+}$ system, the fluorescence quenching curves of $\mathrm{HA}$ at different conditions were shown in Fig. S11 to S18. The decrease in fluorescence intensity with increasing $\mathrm{Pb}^{2+}$ concentrations revealed the formation of chemical complexes between $\mathrm{HA}$ and $\mathrm{Pb}^{2+}$. It was also observed that with the increase of $\mathrm{Pb}^{2+}$ concentration, the maximum emission wavelength of $\mathrm{HA}$ shifted toward the lower wavelength (i.e. blue shift), suggesting the possibility reducing of conjugated bonds in the chain structure, or the occurrence of $\pi-\pi^{\star}$ transition in the reaction process(Zhang et al. 2017). The initial fluorescence intensity of $\mathrm{HA}$ at $\mathrm{pH} 3.0$ was lower than that at $\mathrm{pH} 6.0$, illustrating that $\mathrm{HA}$ has more fluorophore at $\mathrm{pH} 6$, which would help to adsorption more $\mathrm{Pb}^{2+}$ (Gezici et al. 2007).

The linear Stern-Volmer equation was applied to reveal the binding behaviors of $\mathrm{HA}$ with $\mathrm{Pb}^{2+}$, as shown in Fig. 4 and 5, and the model parameter $\mathrm{K}_{\mathrm{SV}}$ was shown in Table 3 . In the ternary system (PSMPs-HA-Pb ${ }^{2+}$ ), the fluorescence quenching of $\mathrm{HA}$ increased with the increase of $\mathrm{pH}$ and the decrease of the ionic strength (both $\mathrm{Na}^{+}$and $\left.\mathrm{Ca}^{2+}\right)$, which was consistent with the trend in the binary system $\left(\mathrm{HA}^{-} \mathrm{Pb}^{2+}\right)$, reflecting in that the addition of PSMPs did not change the binding mode of $\mathrm{HA}$ and $\mathrm{Pb}^{2+}$. Compared to binary system $\left(\mathrm{HA}-\mathrm{Pb}^{2+}\right)$, the fluorescence quenching of $\mathrm{HA}$ in ternary system (PSMPS-HA-Pb ${ }^{2+}$ ) is stronger due to the higher $\mathrm{K}_{\mathrm{sv}}$ value at the same $\mathrm{HA}$ concentration $(5.00 \mathrm{mg} \cdot \mathrm{C} / \mathrm{L})$. In combination with the increase of adsorption of $\mathrm{Pb}^{2+}$ on PSMPs in the presence of HA mentioned above, the results again indicated that part of $\mathrm{Pb}^{2+}$ is indirectly adsorbed on PSMPs with the form of $\mathrm{HA}-\mathrm{Pb}^{2+}$ compound(Fu et al. 2020). In the ternary system, the $\mathrm{K}_{\mathrm{SV}}$ value decreased with the decrease of HA concentration. The initial fluorescence intensity of HA was weak at low concentration, and the change of fluorescence quenching was relatively minor with the increase of $\mathrm{Pb}^{2+}$ concentration. When the concentration of $\mathrm{Pb}^{2+}$ was the maximum, the final fluorescence intensity of $\mathrm{HA}$ under $\mathrm{pH} 3.0$ was always higher than that under $\mathrm{pH} 6.0$, indicating that the binding of $\mathrm{Pb}^{2+}$ to $\mathrm{HA}$ is reduced at low pH due to less exposure of fluorescent groups of HA. There for, the possibility of indirect adsorption of $\mathrm{Pb}^{2+}$ on PSMPs through HA was lower under $\mathrm{pH} 3.0$ condition than that under $\mathrm{pH} 6.0$. 
Table 3

$\mathrm{K}_{\mathrm{sv}}$ value of fluorescence quenching of HA in different systems

\begin{tabular}{|c|c|c|c|c|c|c|c|c|}
\hline system & $\mathrm{pH}$ & $\begin{array}{l}\mathrm{C}_{\mathrm{HA}} \\
(\mathrm{mg} \cdot \mathrm{C} / \mathrm{L})\end{array}$ & $\begin{array}{l}0.100^{\mathrm{a}} \\
(\mathrm{mmol} / \mathrm{L})\end{array}$ & $\begin{array}{l}1.00^{\mathrm{a}} \\
(\mathrm{mmol} / \mathrm{L})\end{array}$ & $\begin{array}{l}10.0^{\mathrm{a}} \\
(\mathrm{mmol} / \mathrm{L})\end{array}$ & $\begin{array}{l}0.0300^{\mathrm{b}} \\
(\mathrm{mmol} / \mathrm{L})\end{array}$ & $\begin{array}{l}0.330^{\mathrm{b}} \\
(\mathrm{mmol} / \mathrm{L})\end{array}$ & $\begin{array}{l}3.33^{\mathrm{b}} \\
(\mathrm{mmol} / \mathrm{L})\end{array}$ \\
\hline \multirow{2}{*}{$\begin{array}{l}\mathrm{HA}- \\
\mathrm{Pb}^{2+}\end{array}$} & 3 & 5.00 & 0.0307 & 0.0271 & 0.0253 & 0.0255 & 0.0242 & 0.0192 \\
\hline & 6 & 5.00 & 0.259 & 0.232 & 0.166 & 0.207 & 0.154 & 0.0880 \\
\hline \multirow{6}{*}{$\begin{array}{l}\text { PSMPs- } \\
\mathrm{HA}^{-} \\
\mathrm{Pb}^{2+}\end{array}$} & \multirow[t]{3}{*}{3} & 1.00 & 0.0267 & 0.0230 & 0.0192 & 0.0257 & 0.0213 & 0.0171 \\
\hline & & 2.50 & 0.0411 & 0.0351 & 0.0294 & 0.0358 & 0.0297 & 0.0227 \\
\hline & & 5.00 & 0.0611 & 0.0460 & 0.0367 & 0.0543 & 0.0399 & 0.0316 \\
\hline & \multirow[t]{3}{*}{6} & 1.00 & 0.138 & 0.112 & 0.100 & 0.123 & 0.108 & 0.0815 \\
\hline & & 2.50 & 0.251 & 0.224 & 0.175 & 0.228 & 0.183 & 0.107 \\
\hline & & 5.00 & 0.379 & 0.279 & 0.248 & 0.306 & 0.278 & 0.217 \\
\hline
\end{tabular}

\section{Conclusion}

In this article, the adsorption of $\mathrm{Pb}^{2+}$ onto PSMPs was studied using batch experiments under different $\mathrm{pH}$ and ionic strength condition, and the effect of HA on the adsorption process was discussed. Under experimental conditions, the adsorption kinetics and isothermal equations of $\mathrm{Pb}^{2+}$ on PSMPs conform to the pseudo-second-order kinetics model and Langmuir model, respectively. The increase of $\mathrm{pH}$ value and decrease of ionic strength was beneficial to the adsorption of $\mathrm{Pb}^{2+}$ on PSMPs regardless of HA presence. The presence of HA enhanced the adsorption capacities of PSMPs for $\mathrm{Pb}^{2+}$. $\mathrm{Pb}^{2+}$ can adsorb onto PSMPs directly through electrostatic interactions, and can also adsorb indirectly through HA.

The site energy distribution of $\mathrm{Pb}^{2+}$ adsorption onto PSMPs under experimental conditions showed that $\mathrm{Pb}^{2+} / \mathrm{HA}-\mathrm{Pb}^{2+}$ firstly occupied the high energy adsorption sites of PSMPs and then diffused to the low-energy adsorption sites. The addition of HA increases the site energy and distribution frequency of $\mathrm{Pb}^{2+}$ on $\mathrm{PSMPs}^{2}$ The heterogeneity of PSMPs at different $\mathrm{pH}$ and ionic strength were similar, indicating that the change of solution conditions did not affect the structure of PSMPs. The fluorescence quenching of HA in ternary systems (PSMPs-HA- $\mathrm{Pb}^{2+}$ ) was stronger than that in binary systems $\left(\mathrm{HA}-\mathrm{Pb}^{2+}\right)$, which proved that $\mathrm{HA}$ encourages the adsorption of $\mathrm{Pb}^{2+}$ on PSMPs. These findings are expected to promote the understanding of the interaction between $\mathrm{Pb}^{2+}, \mathrm{HA}$ and PSMPs for further evaluating the environmental risks of microplastics.

\section{Declarations}

\section{Acknowledgement}

This work was supported by the Natural Science Foundation of China (No. 41877462). 
Author's contribution: Xiaotian Lu, investigation and original draft preparation; Feng Zeng, supervisor, funding support, writing review; Shuyin Wei, data analysis; Rui Gao, sample pretreatment; Abliz Abdurahman, sample collection; Hao Wang, sample collection; Weiqian Liang, writing review.

Data availability: not applicable.

Ethical Approval: Not applicable.

Competing interests: The authors declare that they have no conflict of interesting.

Consent to participate: All authors have given consent to their contribution.

Consent for publication: All authors have agreed with the content and all have given explicit consent to publish.

\section{Appendix A. Supplementary data}

\section{References}

Abdurahman, A., Cui, K., Wu, J., Li, S., Gao, R., Dai, J., Liang, W. and Zeng, F. 2020. Adsorption of dissolved organic matter (DOM) on polystyrene microplastics in aquatic environments: Kinetic, isotherm and site energy distribution analysis. Ecotoxicology and Environmental Safety 198, 110658.

Ahechti, M., Benomar, M., El Alami, M. and Mendiguchía, C. 2020. Metal adsorption by microplastics in aquatic environments under controlled conditions: exposure time, $\mathrm{pH}$ and salinity. International Journal of Environmental Analytical Chemistry, 1-8.

Alimi, O.S., Budarz, J.F., Hernandez, L.M. and Tufenkji, N. 2018. Microplastics and Nanoplastics in Aquatic Environments: Aggregation, Deposition, and Enhanced Contaminant Transport. Environmental Science \& Technology 52(4), 1704-1724.

Arthur, C., Baker, J., Bamford, H., Barnea, N. and Mcelwee, K. 2009. Summary of the international research workshop on the occurrence, effects, and fate of microplastic marine debris.

Bardestani, R., Roy, C. and Kaliaguine, S. 2019. The effect of biochar mild air oxidation on the optimization of lead(II) adsorption from wastewater. Journal of Environmental Management 240, 404-420.

Bellinger, D.C. and Needleman, H.L. 2003. Intellectual impairment and blood lead levels. New England Journal of Medicine 349(5), 500-502.

Bradl, H.B. 2004. Adsorption of heavy metal ions on soils and soils constituents. Journal of Colloid \& Interface Science 277(1), 1-18.

Brennecke, D., Duarte, B., Paiva, F., Ca Ador, I. and Ca Nning-Clode, J. 2016. Microplastics as vector for heavy metal contamination from the marine environment. Estuarine Coastal and Shelf Science 178, 189-195. 
Carter, M.C., Kilduff, J.E. and Weber, W.J. 1995. Site energy distribution analysis of preloaded adsorbents. Environmental Science \& Technology 29(7), 1773-1780.

Coble, P.G. 1996. Characterization of marine and terrestrial DOM in seawater using excitation-emission matrix spectroscopy. Marine Chemistry 51(4), 325-346.

Desforges, J.W., Galbraith, M., Dangerfield, N. and Ross, P.S. 2014. Widespread distribution of microplastics in subsurface seawater in the NE Pacific Ocean. Marine Pollution Bulletin 79(1-2), 94-99.

Fu, Q., Tan, X., Ye, S., Ma, L. and Tang, Y. 2020. Mechanism analysis of heavy metal lead captured by naturalaged microplastics. Chemosphere 270, 128624.

Gao, F., Li, J., Sun, C., Zhang, L., Jiang, F., Cao, W. and Zheng, L. 2019. Study on the capability and characteristics of heavy metals enriched on microplastics in marine environment. Marine Pollution Bulletin $144,61-67$.

Gezici, O., Kara, H., Yanık, S., Ayyildiz, H. F. and Kucukkolbasi, S. 2007. Investigating sorption characteristics of copper ions onto insolubilized humic acid by using a continuously monitored solid phase extraction technique. Colloids and Surfaces A: Physicochemical and Engineering Aspects 298(1-2), 129-138.

Hus, P. and Guo, Y.L. 2002. Antioxidant nutrients and lead toxicity. Toxicology 180, 33-44.

Godoy, V., Blazquez, G., Calero, M., Quesada, L. and Martin-Lara, M.A. 2019. The potential of microplastics as carriers of metals. Environmental Pollution 255(3), 113363.113361-113363.113312.

Hidalgo-Ruz, V., Gutow, L., Thompson, R.C. and Thiel, M. 2012. Microplastics in the Marine Environment: A Review of the Methods Used for Identification and Quantification. Environmental Science \& Technology 46(6), p.3060-3075.

Hodson, M.E., Duffus-Hodson, C., Clark, A., Prendergast-Miller, M.T. and Thorpe, K.L. 2017. Plastic Bag Derived-Microplastics as a Vector for Metal Exposure in Terrestrial Invertebrates. Environmental Science \& Technology 51(8), 4714-4721.

Holmes, L.A., Turner, A. and Thompson, R.C. 2014. Interactions between trace metals and plastic production pellets under estuarine conditions. Marine Chemistry 167, 25-32.

Huang, L., Jin, Q., Tandon, P., Li, A., Shan, A. and Du, J. 2018. High-resolution insight into the competitive adsorption of heavy metals on natural sediment by site energy distribution. Chemosphere 197, 411.

Jozef, K., Sawomir, D., Magdalena, W.K. and Petr, B. 2020. Uptake and phytotoxicity of lead are affected by nitrate nutrition and phenolic metabolism. Environmental and Experimental Botany, 104158.

Kováik, J., Bujdo, M. and Babula, P. 2018. Impact of humic acid on the accumulation of metals by microalgae. Environmental Science and Pollution Research 25(8), 1-7. 
Lee, J.W., Choi, H., Hwang, U.K., Kang, J.C., Kang, Y.J., Kim, K.I. and Kim, J.H. 2019. Toxic effects of lead exposure on bioaccumulation, oxidative stress, neurotoxicity, and immune responses in fish: A review. Environmental Toxicology and Pharmacology.

Lei, L., Wu, S., Lu, S., Liu, M. and He, D. 2018. Microplastic particles cause intestinal damage and other adverse effects in zebrafish Danio rerio and nematode Caenorhabditis elegans. Science of The Total Environment 619-620, 1-8.

Li, S., Liu, H., Gao, R., Abdurahman, A., Dai, J. and Zeng, F. 2018. Aggregation kinetics of microplastics in aquatic environment: Complex roles of electrolytes, $\mathrm{pH}$, and natural organic matter. Environmental Pollution 237, 126-132.

Li, X., Ma, L., Li, Y., Wang, L. and Zhang, L. 2019. Endophyte infection enhances accumulation of organic acids and minerals in rice under $\mathrm{Pb}(2+)$ stress conditions. Ecotoxicology and Environmental Safety 174, 255262.

Li, X., Mei, Q., Chen, L., Zhang, H. and Dong, B. 2019. Enhancement in adsorption potential of microplastics in sewage sludge for metal pollutants after the wastewater treatment process. Water Research 157, $228-237$.

Liao, P., Li, B., Xie, L., Bai, X., Qiao, H., Li, Q., Yang, B. and Liu, C. 2020. Immobilization of Cr(VI) on engineered silicate nanoparticles: Microscopic mechanisms and site energy distribution. Journal of Hazardous Materials 383, 121145.121141-121145.121110.

Liu, W., Sun, W., Han, Y., Ahmad, M and Ni, J. 2014. Adsorption of Cu(II) and Cd(II) on titanate nanomaterials synthesized via hydrothermal method under different $\mathrm{NaOH}$ concentrations: Role of sodium content. Colloids \& Surfaces A Physicochemical \& Engineering Aspects 452, 138-147.

Lu, S., Zhu, K., Song, W., Gang, S., Chen, D., Hayat, T., Alharbi, N.S., Chen, C. and Sun, Y. 2018. Impact of water chemistry on surface charge and aggregation of polystyrene microspheres suspensions. Science of The Total Environment 630, 951.

Lu, Y., Yan, Z., Deng, Y., Wei, J., Zhao, Y., Geng, J., Ding, L. and Ren, H. 2016. Uptake and Accumulation of Polystyrene Microplastics in Zebrafish (Danio rerio) and Toxic Effects in Liver. Environmental Science \& Technology 50(7), 4054-4060.

Luo, H., Liu, C., He, D., Xu, J., Sun, J., Li, J. and Pan, X. 2022. Environmental behaviors of microplastics in aquatic systems: A systematic review on degradation, adsorption, toxicity and biofilm under aging conditions. Journal of Hazardous Materials 423, 126915.

Ma, H., Allen, H.E. and Yin, Y. 2001. Characterization of isolated fractions of dissolved organic matter from natural waters and a wastewater effluent. Water Research 35(4), 985-996.

Prado, A., Torres, J.D., Martins, P.C., Pertusatti, J., Bolzon, L.B. and Faria, E.A. 2006. Studies on copper(II)- and zinc(II)-mixed ligand complexes of humic acid. Journal of Hazardous Materials 136(3), 585-588. 
Qi, K., Lu, N., Zhang, S., Wang, W. and Guan, J. 2021. Uptake of Pb(II) onto microplastic-associated biofilms in freshwater: Adsorption and combined toxicity in comparison to natural solid substrates. Journal of Hazardous Materials 411(6), 125115.

Qiao, X., Hu, F., Tian, F., Hou, D. and Li, D. 2016. Equilibrium and kinetic studies on MB adsorption by ultrathin 2D MoS2 nanosheets. RSC Adv. 6.

Rodriguez-Seijo, A., Lourenco, J., Rocha-Santos, T., Costa, J.D., Duarte, A.C., Vala, H. and Pereira, R. 2016. Histopathological and molecular effects of microplastics in Eisenia andrei Bouché. Environmental Pollution, 495-503.

Shen, M., Song, B., Zeng, G., Zhang, Y. and Zhou, C. 2021. Surfactant changes lead adsorption behaviors and mechanisms on microplastics. Chemical Engineering Journal 405, 126989.

Shi, H., Sun, Y., Zhao, X. and Qu, B. 2013. Influence on Sorption Property of Pb by Fractal and Site Energy Distribution about Sediment of Yellow River. Procedia Environmental Sciences 18, 464-471.

Sun, H., Xin, S., Mao, J. and Zhu, D. 2010. Tetracycline sorption to coal and soil humic acids: An examination of humic structural heterogeneity. Environmental Toxicology \& Chemistry 29(9), 1934-1942.

Tan, M., Liu, L., Zhang, M., Liu, Y. and Li, C. 2021. Effects of solution chemistry and humic acid on the transport of polystyrene microplastics in manganese oxides coated sand. Journal of Hazardous Materials $413,125410$.

Tan, W., Xiong, J., Li, Y., Wang, M., Weng, L. and Koopal, L.K. 2013. Proton binding to soil humic and fulvic acids: Experiments and NICA-Donnan modeling. Colloids and Surfaces A: Physicochemical and Engineering Aspects 436, 1152-1158.

Tang, S., Lin, L., Wang, X., Feng, A. and Yu, A. 2019. Pb(II) uptake onto nylon microplastics: Interaction mechanism and adsorption performance. Journal of Hazardous Materials 386.

Tarnminga, Matthias, Paglialonga, Lisa, Fischer, Kerstin, E., Czech and Elisa 2016. Microplastic pollution in lakes and lake shoreline sediments - A case study on Lake Bolsena and Lake Chiusi (central Italy). Environmental Pollution.

Wang, C., Fan, X., Wang, P., Hou, J., Ao, Y. and Miao, L. 2016. Adsorption behavior of lead on aquatic sediments contaminated with cerium dioxide nanoparticles. Environmental Pollution 219, 416-424.

Wang, F., Yang, W., Cheng, P., Zhang, S., Zhang, S., Jiao, W. and Sun, Y. 2019. Adsorption characteristics of cadmium onto microplastics from aqueous solutions. Chemosphere 235, 1073-1080.

Wang, Q., Zhang, Y., Wangjin, X., Wang, Y., Meng, G. and Chen, Y. 2020. The adsorption behavior of metals in aqueous solution by microplastics effected by UV radiation. Journal of Environmental Sciences 87, 272-280.

Wang, X. 2011. Batch sorption of lead (II) from aqueous solutions using natural kaolinite. International Journal of Environment and Waste Management 8(3-4), 258-272. 
Wang, Y., Wang, X., Li, Y., Li, J. and Zhao, J. 2020. Biofilm alters tetracycline and copper adsorption behaviors onto polyethylene microplastics. Chemical Engineering Journal 392, 123808.

Wijesena, R.N., Tissera, N.D., Rathnayaka, V., Silva, R. and Silva, K. 2020. Colloidal stability of chitin nanofibers in aqueous systems: Effect of $\mathrm{pH}$, ionic strength, temperature \& concentration. Carbohydrate Polymers 235, 116024.

Xiong, J., Koopal, L.K., Tan, W.F., Fang, L.C., Wang, M.X., Zhao, W., Liu, F., Zhang, J. and Weng, L.P. 2013. Lead Binding to Soil Fulvic and Humic Acids: NICA-Donnan Modeling and XAFS Spectroscopy. Environmental Science \& Technology 47(20), 11634-11642.

Xu B., Liu F., Philip C.B and Xu J. 2018. Microplastics play a minor role in tetracycline sorption in the presence of dissolved organic matter - ScienceDirect. Environmental Pollution 240, 87-94.

Yan, B., Niu, C. and Wang, J. 2017. Analyses of Levofloxacin Adsorption on Pretreated Barley Straw with Respect to Temperature: Kinetics, $\pi-\pi$ Electron-Donor-Acceptor Interaction and Site Energy Distribution. Environmental Science \& Technology 122(14), 128.

Yang, K., Miao, G., Wu, W., Lin, D. and Xing, B. 2015. Sorption of $\mathrm{Cu}(2+)$ on humic acids sequentially extracted from a sediment. Chemosphere 138, 657-663.

Yang, S., Hu, J., Chen, C., Shao, D. and Wang, X. 2011. Mutual effects of Pb(II) and humic acid adsorption on multiwalled carbon nanotubes/polyacrylamide composites from aqueous solutions. Environmental Science \& Technology 45(8), 3621.

Yang, S., Li, L., Pei, Z., Li, C., Shan, X.Q., Wen, B., Zhang, S., Zheng, L., Zhang, J. and Xie, Y. 2014. Effects of humic acid on copper adsorption onto few-layer reduced graphene oxide and few-layer graphene oxide. Carbon 75(1), 227-235.

Zhang, Z., Lü, C., Jiang, H., Gao, M. and Yu, Z. 2017. Nature differences of fulvic acid fractions induced by extracted sequence as explanatory factors for binding characteristics of $\mathrm{Cu}^{2+}$. Chemosphere 191(10), 458466 .

Zhao, G., Li, J., Ren, X., Chen, C. and Wang, X. 2011. Few-Layered Graphene Oxide Nanosheets As Superior Sorbents for Heavy Metal Ion Pollution Management. Environmental Science \& Technology 45(24), 1045410462.

Zheng, H., Yang, G., Zhu, K., Wang, Q., Wakeel, M., Abdul, W., Alharbi, N.S. and Chen, C. 2018. Investigation of the adsorption mechanisms of $\mathrm{Pb}(\mathrm{II})$ and 1-naphthol by $\beta$-cyclodextrin modified graphene oxide nanosheets from aqueous solution. Journal of Colloid and Interface science 530, 154-162.

Zou, J., Liu, X., Zhang, D. and Yuan, X. 2020. Adsorption of three bivalent metals by four chemical distinct microplastics. Chemosphere 248, 126064.

\section{Figures}



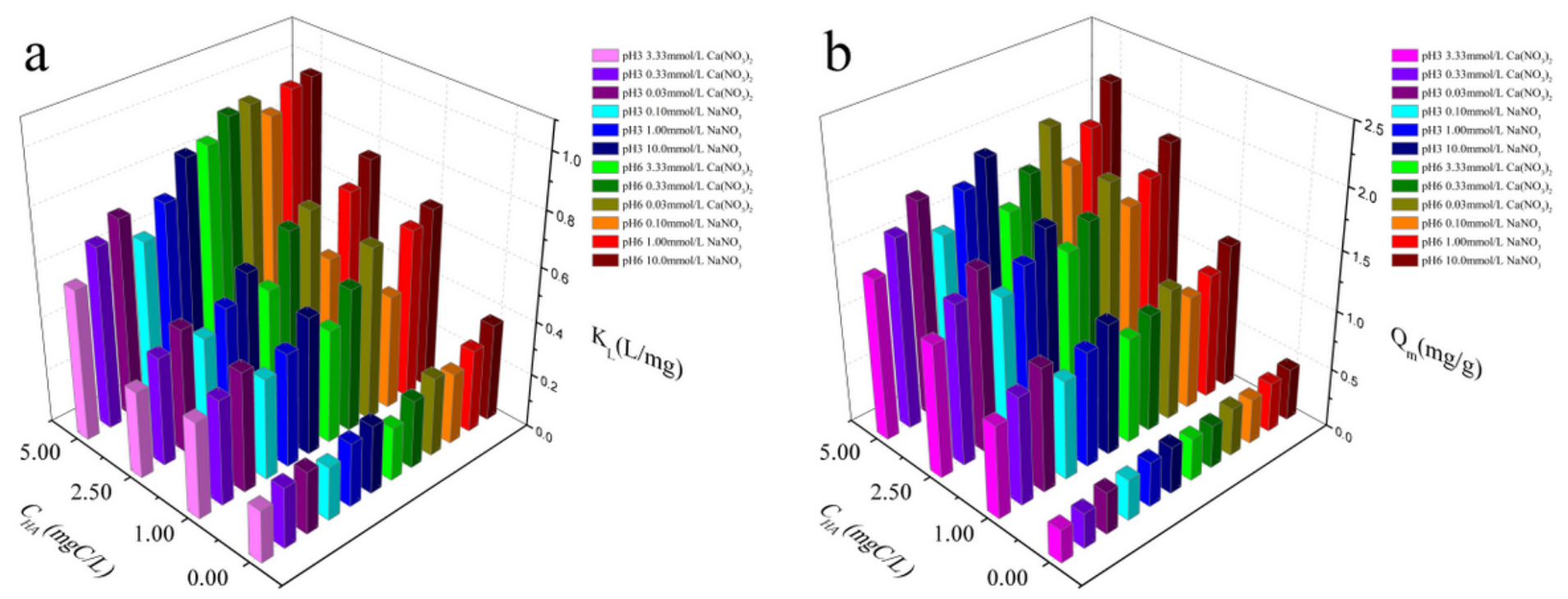

Figure 1

Comparison of Langmuir model parameters $\mathrm{KL}$ and Qm under different conditions
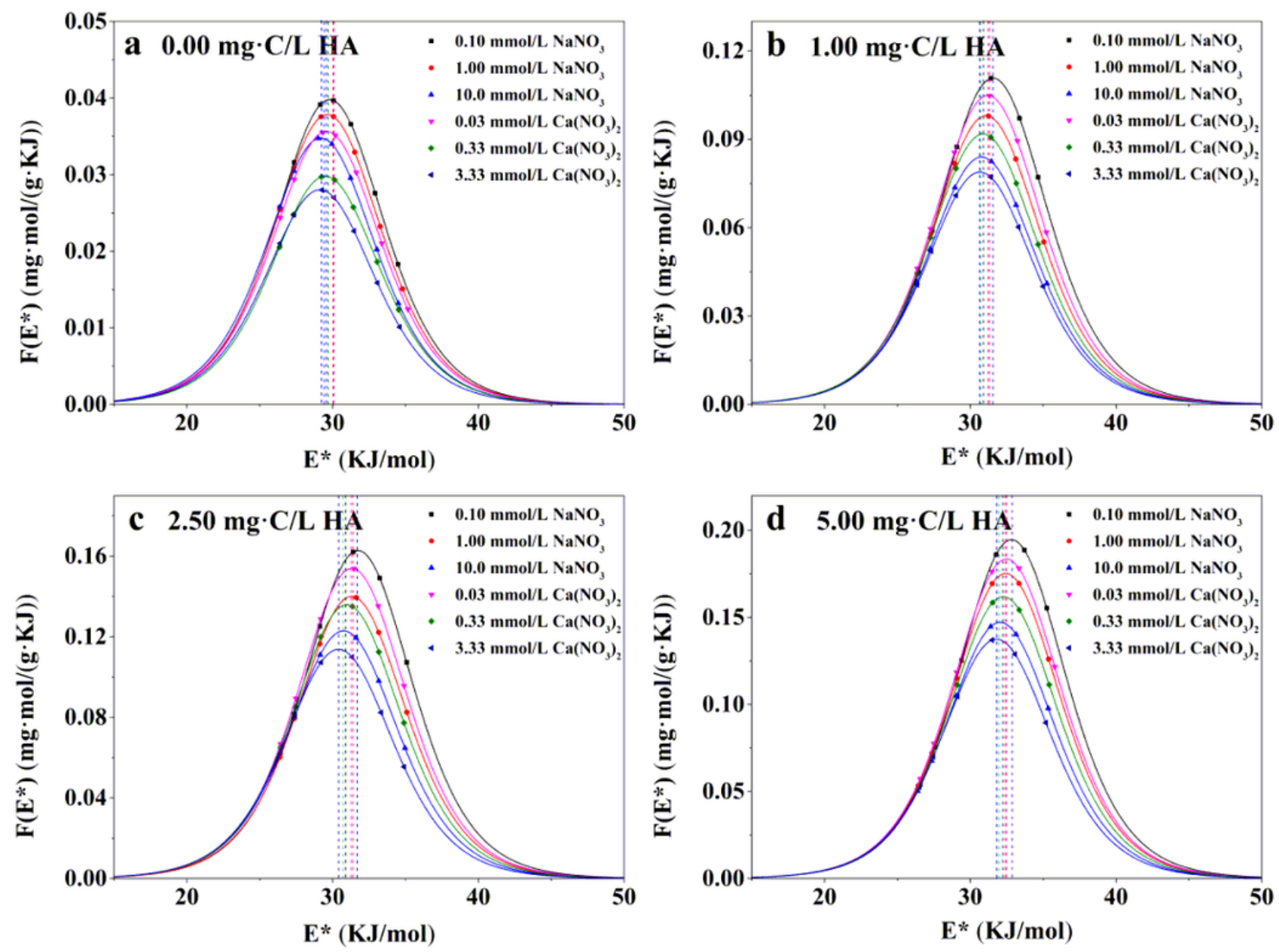
Figure 2

Site energy distribution curves $\mathrm{F}\left(\mathrm{E}^{\star}\right)$ of $\mathrm{Pb} 2+$ adsorption onto PSMPs $(\mathrm{pH} 3.0)$
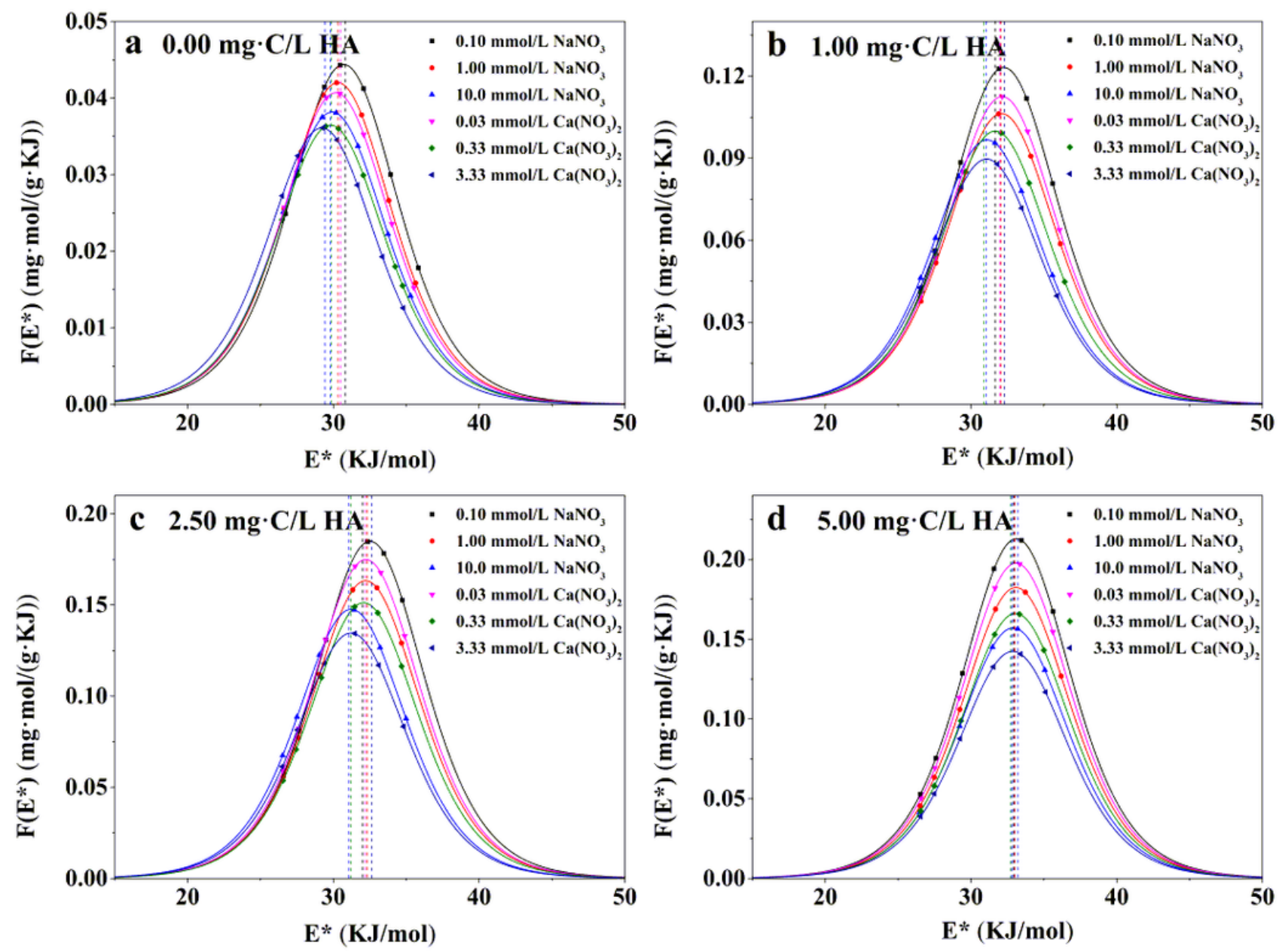

Figure 3

Site energy distribution curves $\mathrm{F}\left(\mathrm{E}^{\star}\right)$ of $\mathrm{Pb} 2+$ adsorption onto PSMPs $(\mathrm{pH} 6.0)$ 

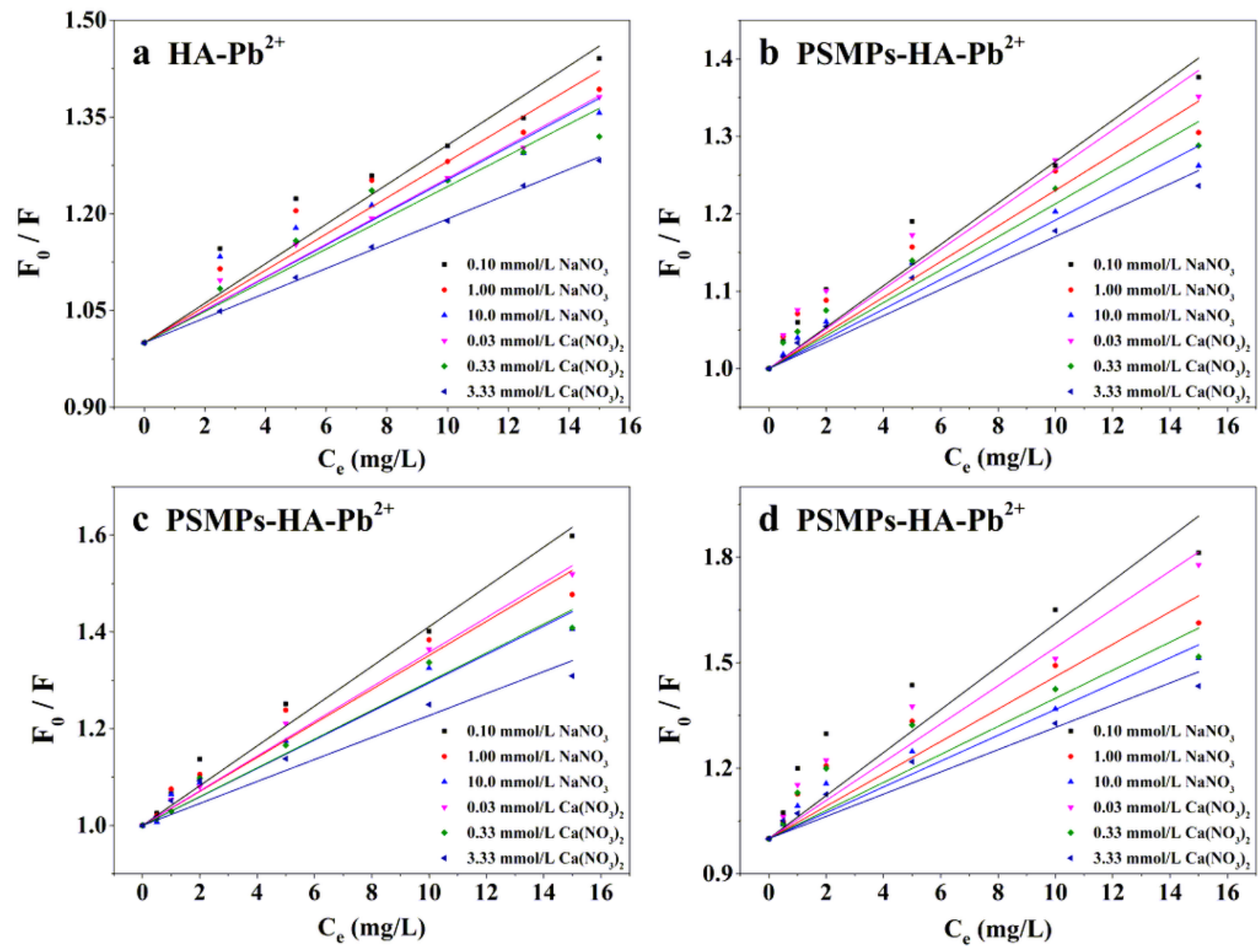

Figure 4

The linear Stern-Volme fitting curves of HA fluorescence quenching process $(\mathrm{pH} 3.0)(\mathrm{a} .5 .00 \mathrm{mg} \cdot \mathrm{C} / \mathrm{L} \mathrm{HA} ; \mathrm{b}$. $1.00 \mathrm{mg} \cdot \mathrm{C} / \mathrm{L} \mathrm{HA} ; \mathrm{C} .2 .50 \mathrm{mg} \cdot \mathrm{C} / \mathrm{L} \mathrm{HA}$; d. $5.00 \mathrm{mg} \cdot \mathrm{C} / \mathrm{L} \mathrm{HA}$ ) 

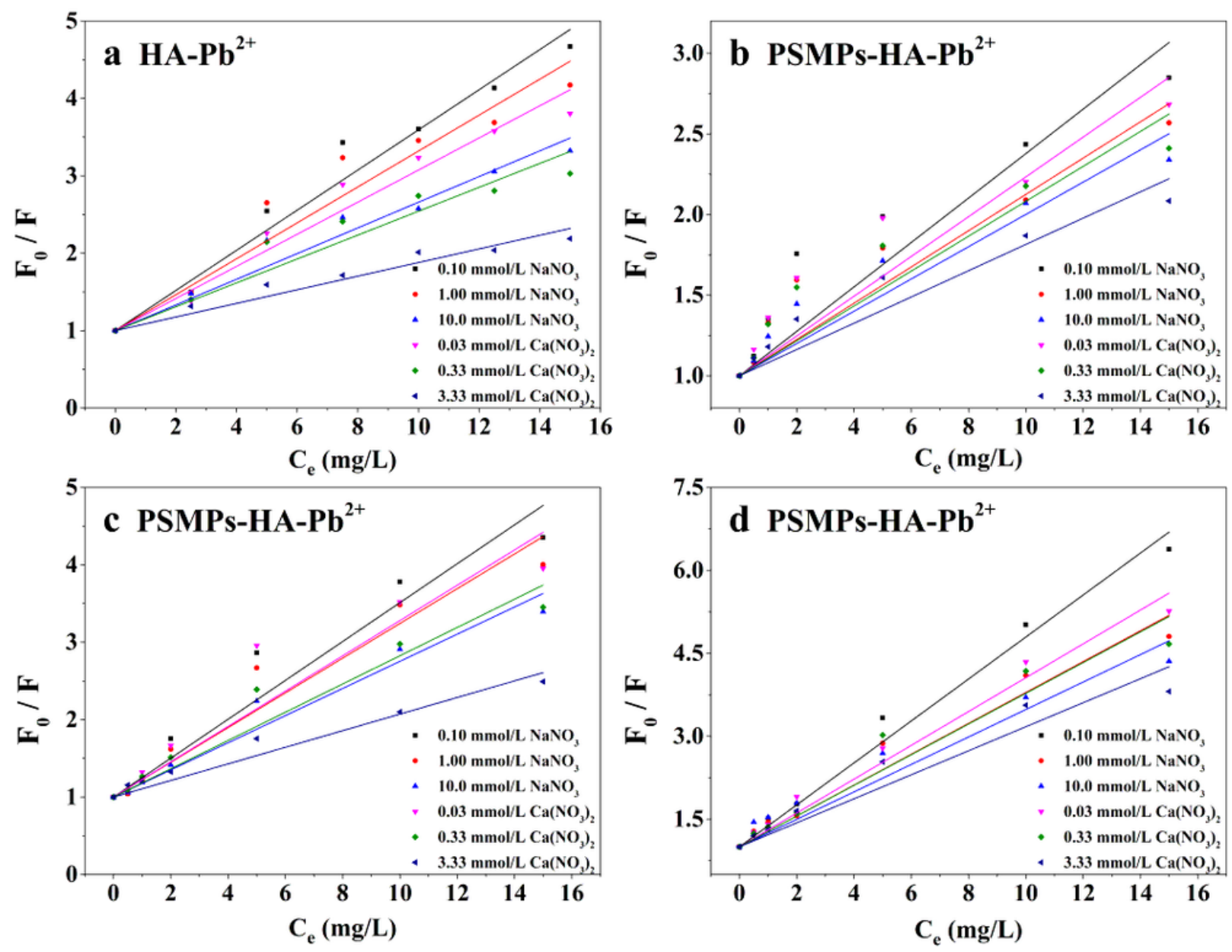

Figure 5

The linear Stern-Volme fitting curves of HA fluorescence quenching process $(\mathrm{pH} 6.0)(\mathrm{a} .5 .00 \mathrm{mg} \cdot \mathrm{C} / \mathrm{L} \mathrm{HA} ; \mathrm{b}$. $1.00 \mathrm{mg} \cdot \mathrm{C} / \mathrm{L} \mathrm{HA} ; \mathrm{C} .2 .50 \mathrm{mg} \cdot \mathrm{C} / \mathrm{L} \mathrm{HA}$; d. $5.00 \mathrm{mg} \cdot \mathrm{C} / \mathrm{L} \mathrm{HA})$

\section{Supplementary Files}

This is a list of supplementary files associated with this preprint. Click to download.

- SupplementaryInformation.docx 